British Journal of Education, Society \&
Behavioural Science
$15(2):$ 1-9, 2016, Article no.BJESBS.24984
ISSN: 2278-0998
SCIENCEDOMAIN international
Www.Sciencedomain.org

\title{
Quality of Life and Sexuality among People with Mental and Physical Disabilities in the Italian Context
}

\author{
M. Garro ${ }^{1}$, A. Merenda ${ }^{1^{\star}}$ and A. Salerno ${ }^{1}$ \\ ${ }^{1}$ Department of Scienze Psicologiche, Pedagogiche e della Formazione, University of Palermo, Italy.
}

Authors' contributions

This work was carried out in collaboration between all authors. All authors read and approved the final manuscript.

Article Information

DOI: $10.9734 / B J E S B S / 2016 / 24984$

Editor(s):

(1) Redhwan Ahmed Mohammed Al-Naggar, Management and Science University, Malaysia.

Reviewers:

(1) Alexandre Martins Valenca, Fluminense Federal University, Niteroi, Rio de Janeiro, Brazil.

(2) Joyce Kinaro, University of Nairobi, Nairobi, Kenya. (3) Mario Bernardo-Filho, Universidade do Estado do Rio de Janeiro, Brazil. Complete Peer review History: http://sciencedomain.org/review-history/13947

Review Article

Received $11^{\text {th }}$ February 2016

Accepted 18 $8^{\text {th }}$ March 2016

Published $30^{\text {th }}$ March 2016

\section{ABSTRACT}

Aim: The article analyses sexuality and quality of life among people with mental and physical disabilities in the Italian context. It is aimed at contributing to a social debate over the sexual assistant for disabled people, as this professional is not still present in Italy. The aim of this paper is therefore to reflect on the consequences of the negative attitudes towards sexual life in disabled people, as well as for their families and community.

In the collective unconscious, people with physical or mental disabilities are considered unable to live a healthy sexuality. This representation contributes to the spread of false attributions and prejudices. These characteristics may also be found inside the familiar context and its parental, educational style that appears so overprotective of the disabled child, in an attempt to relieve him of any social comparisons.

Conclusion: The article was aimed at encouraging a social and political debate towards the introduction of a sexual assistant in Italy where, this professional still not has an institutional recognition. Disabled people's sexual needs and desires cannot longer be ignored. A long pathway 
should be undertaken to promote their well-being, towards a dynamic process of change aimed at improving the quality of life of disabled people, their family and community as well.

Keywords: Quality of life; sexuality; disability; Italian context.

\section{INTRODUCTION}

The Convention on the Rights of Persons with Disabilities and its Optional Protocol (A/RES/61/106(CRPD, 2006), adopted by the General Assembly of the United Nations, recognises the sexuality and sexual health services Right (art.23 and 25) for all those individuals - for temporary or permanent, reversible or irreversible, or even progressive or regressive conditions - who cannot perform an activity in the way or within the range considered normal for a human being. This is pointed out by the International Classification of Functioning, Disability and Health (ICF, 2001), who pay particular consideration to the relationship with the different contexts that affect their life conditions.

The achievement of human rights is therefore connected to sexual rights, as well as the promotion of human development, which necessarily involves sexuality and sexual health (WHO, 2004, 2011; WAS, 2008) [1]. The last one, in particular, consists of the integration of a sexual being's somatic, emotional, intellectual and social aspects, in a way that enhances personality, communication and love. All individuals have the right to information and pleasure (WHO, 1975). The approach to sexuality is often denied because of social representation that assigns disabled people the roles of: sexless, uninterested in sex or unable to partake in sexual activities, or even as "monsters" who are unable to control sexual impulses and feelings [2]. The important role of the media, conveying messages, has indisputably a strong function of orienting cultural patterns and practices of reference, investing principles of appearance and consumption that often exclude those who do not have the resources to access it $[3,4]$. Disabled Sexuality, in fact, has little representation and little social media coverage. It has no impact on the market, does not feed the cult of pursued and prosecuted beauty, meaning, therefore, that the sexual needs of the disabled are confined to the disappearance of the body. Disabled sexuality, therefore, not in line to dominant models, is relegated to a relational dimension in close connection with the practices of border and personal hygiene or bodily functions [5-8].

The exclusion from everyday representations of disabled people's emotional needs strengthens, therefore, myths and cultural representations that inevitably seem to have significant effects even in the planning and design of community services, in community disparities in terms of delivery service or, moreover, in the levels of health services inadequate to meet needs and desires, sometimes unutterable in disability [9].

In Italy, in particular, where there are currently 2.8 million people with disabilities, access to information on sexual rights, as well as to sexual services, is severely limited despite international documents and increased awareness of the issue $[10,11]$. Moreover, sexual care services for disabled people in the Italian context are still not present, whereas they have already established in other countries, such as : Netherlands (since 1980), Germany (since 1959), GermanSwitzerland (since 2003) and French-Switzerland (since 2009), Scandinavian countries (e.g. Denmark, since 1978) [12-14]. This type of assistance refers to the performance of a professional (man or woman) with a bisexual, heterosexual or homosexual orientation, who supports people with disabilities to experience eroticism and sexuality. The beneficiaries of the service, under such experiences, could have the opportunity to increase awareness of themselves and their emotional and sexual relationships, to promote a to promote a greater knowledge and more adequate capacity to take care of their own body and person [15].

The aim of this paper is therefore to reflect on the consequences of the negative attitudes towards quality of sexual life in disabled people, as well as for their families and community. For this reason, the article is aimed at encouraging a social and political debate towards the introduction of a sexual assistant in Italy where, this professional still not has an institutional recognition. According with the scientific literature, disabled people's sexual needs and desires cannot longer be ignored. The promotion of their well being as well as their human rights cannot be dismissed and neglecting their 
psycho-sexual needs is considered as a failure [16].

\section{SEXUALITY AND DISABILITY}

Several studies highlight the absence of a total coincidence between sexuality and "genitality" $[17,18]$, considering several important aspects related to sexual life, such as bodily and physical contact, tenderness and affection dimensions. And when sexuality is not associated with "genitality" it involves the enhancement of other aspects of human emotional life, in order to avoid inadequate information and simple explanations. An appropriate sexual education and correct information would indeed promote important safe behaviours as well as could allow disabled people to tell if they were victims of violence (or let them to reveal any violence episodes they could have suffered [19-21]. This is also so important if we remember their high risk of abuse and maltreatment in a percentage from 2 to 5 times greater than that recorded by the general population [22]. The real risk is considered by the sixteenth article of the ONU Convention (Right to not be submitted to exploitation, violence and abuse, Law 18/09) which starts with activities, services and survey data that take into account victims or potential victims with disabilities (more often women or minors). In Italy, this issue has demonstrated strong sensitivity through the activation of the "Special Action Plan against sexual and gender violence" (D.L., $14^{\text {th }}$ August 2013, n. 93. http://www.pariopportunita.gov.it/).

Sexuality in disability represents a topic with many approaches, taking into account different types of disabilities. Indeed, many studies show more negative stereotypes, greater social distance and withdrawal behaviours towards people with intellectual disabilities, compared to those with physical disabilities $[22,23]$. Moreover, a low level of acceptance and perception of threat, associated with a greater social distance, as well as a low perception of rights are all attitudes considered important for disabled people for their ability to achieve their social and psychological needs. In Europe, seven million intellectual disabled people are deprived of the opportunity to start a romantic relationship, have sex, get married or have children, because they have to constantly deal with social attitudes, professionals and, above all, their families [24].

The misinformation about sexuality in general and even misconceptions about sexuality in disability are often transmitted by health professionals and parents [25]. In Italy, in particular, $93 \%$ of disabled people live with their family (Istat, 2009), with conservative attitudes regarding a child's sexuality. Parental overprotection, in fact, hinders a child's bodily exploration or auto-eroticism, preventing the healthy development of a sexual identity and self-awareness as a sexual human being. Moreover, it interferes with sexual self-esteem as well as the self-perception of being a good partner [26].

\section{SEXUALITY AND AFFECTION AMONG FAMILY AND COUPLE WITH A DISABLED PARTNER}

Living corporeality and sexuality in terms of disability opens complex and various scenarios. The subject and his family environment are primarily involved inside a specific developmental path of construction of a sexual identity. Sexual development studies clarify the importance of bodily and emotional components, both of which are related to the relational sphere. If the first refers to the "genitality" and technical or physical performance, the second one recognises, instead, the importance of intimacy that makes the relationship between partners unique. But living with a disability is still considered as living without the need of these two components or as "an asexual who by not being strong, healthy and beautiful, is just weak" [27,125].

As Salonia [28] shows the body is considered the centre for child development. He affirms that each growth phase is determined by the gradual emergence and differentiation of interest-energy (libido) to/from specific areas of the body, such as the sphincters (oral and anal) and genitals (male and female). Actually, many theoretical and clinical models use the body/mind relationship in a reciprocal way. For example, Psychoanalysis starts from mental representation, Bioenergetics from bodily experience, while Gestalt Therapy (GT) reassembles the body/mind split looking at the human organism as a whole dynamic unit and in connection with its environment. In other words, attention to the live body allows for a genuine expression of intimate meanings of the human organism. Like a compass, GT can indicate to the subject how he is experiencing the situation (e.g. the meanings of his innermost being-in-theworld-in-this-specific moment), but not only at a cognitive level but at a bodily one too. For example, if we feel anger and if we feel it in the 
body in all its intensity, then it is possible to understand the reasons for it and how to regulate it too [28].

In a disabled person, it is precisely the achievement of such integration which requires an organism-environment encounter in which the disabled person can experience the functionality of one's body, by increasing the experience from the development of childhood, a constitutive element of corporeal identity. Moreover, focus on a disabled person's bodily experiences also allows for a response to his familiar context. Although studies on the psychosocial impact and consequences in a family that faces disability have seen a progressive enrichment of perspectives, the attention is still focused on the role of "de-synchronisations" during the family life cycle [29]. In other words, family in front of the disability would lie in a border between health and disease, normative and deviant aspects. The birth of a child with disabilities is considered as a "para-normative" or unexpected event that puts the family in front of a high level of emotional stress, for which each family will react according to their internal and social energy and resources. The path to cross that event is tortuous and painful and contemplating child sexuality is very difficult: "children are considered eternal children, and when parents observe some sexual signals, already present in puberty, they tend to keep a distance, calling them innocent fantasies or behaviours to prohibit and ban" $[30,56]$.

The birth of a child with a disability is a traumatic paranormal event that can stop the course of time for the family by blocking the ability for the family to move beyond the present moment. Suddenly, the future can become emotionally unpredictable or unimaginable. The past, with all its hopes and fantasies related to the period of pregnancy, is erased. Parents become prisoners of a present that seems to have no end. Even the social value, limited to the disease, takes on a negative connotation: the disability of a child becomes the disability of the whole family, which stops or inhibits interactions with other families or the community, losing the emotional and symbolic functions related to the intermediation process with the outside world. After the initial shock and during the restructuring of familiar roles, parents (especially the mother) carry out a function of support and care for their child. Then, an attitude of parental overprotection begins to set in and sometimes this can prevent the development of the personality and the residual skills of the child, amplifying his emotional and relational difficulties. A significant example concerns the denial of sexuality in people with disabilities, considered the perennial children with infantile needs [31].

The family continues to consider with reticence the affective-relational sphere related to the sexuality of physically and mentally disabled people, as well their desire to love and have a partner. In fact, the familiar complexity often makes it impossible for them to create their own family with disabled people. The convention on disability rights (http://www.un.org/disabilities/convention/conven tionfull.shtml, drafted 13 Dec 2006) recognises the right of all people with disabilities, if they are at an age of marriage, to marry and create a family on the basis of their full and free consent (www.unicef.it). Disabled people who attend community centres or public and private services have more opportunities to create friendships or romantic relationships, because sharing the same reality unites them and enables them to feel understood or part of a group [32].

In the last decade, it has been shown that more couples live together with the same handicap and, albeit in a small number, there are couples where only one partner is living with a disability: "those who choose to be accompanied by a person with a disability are not choosing the disability but a person with whom to engage and compare themselves" [30,97]. By carefully distinguishing every disability (physical and mental), more categories to be assessed concern the type and intensity of impairment, where it does not arise in the same manner and with the same characteristics as it is linked to variables such as: the type and severity of the deficit, the family network and extra family relationships, age or sex [31].

The sexual component of the partnership can be expressed in different ways depending on the type of impairment present, but it has to be considered in any case. Major difficulties can arise from the idealisation of the partner or from the underestimation of his bodily experiences which, as already mentioned, can play an important role even more so if it is connected to the functional impairments, for example: malformations in terms of affecting posture and/or functionality, impairments and degenerative diseases that lead to a loss of muscle strength, and injuries that may affect the sensitivity and functionality of sexual organs. Often the fear that the relationship with those 
who are disabled is based only on health care discourages the approach to these relations. As with each couple, also when a person with disabilities is present, the need to support each other is important even where physical limitations do not allow for total (or partial) autonomy. Especially in these situations, the perception of the sphere of intimacy can become, in a negative sense, a fear or a worry [32].

However, with couples in which the presence of an average physical or mental impairment has allowed the transition to parenthood, parental function is carried out taking into account certain difficulties. In those situations where one of the parents with a cognitive or motor impairment is unable to provide for the basic needs of the children, the presence of the other parental partner can compensate them. But, when the impairment is very serious in both parents it is necessary to remove children from their homes and place them into foster care or seek adoption [27].

\section{THE IMPACT OF DISABILITY ON THE COUPLE'S LIFE. AREAS OF INTERVENTION}

Although literature on the influence of disability in regards to the well-being of the couple is rather limited, some critical areas were outlined to us in a more in-depth analysis. Esmail et al. [34], in this regard, might wish to: compare the characteristics of the couple's sexual life before and after the onset of disability; dwell on any change in the roles, expectations and gender differences related to the adaptation to disability both in the partner carrier of the disease, as well as in the healthy partner; distinguish the impairment in the expressions on a physical level of sexuality as well as the ability to maintain intact events of intimacy and emotional complicity; and identify the most effective strategies of psychotherapeutic intervention for couples who request it [33].

With regard to this point, it is common to find a lack and inadequacy of the initiatives related to the specific training of professionals in the field of psychology: the same psychologists, counsellors and psychotherapists who say they are unprepared and not at ease in dealing with issues related to the consequences of disability on sexuality, noting that, in general, in support services to mental health sexuality does not receive adequate attention and training opportunities, and these aspects are often sketchy $[35,36]$. In addition, it is important that professionals reflect first on their personal ideas about the connection between illness, disability and sexuality in the awareness of being strongly affected when they are working with couples who are carriers of these topics.

Although there is little research on how the couple therapists (who, more than others, deal with issues related to the sphere of sexuality) perceive couples with disabilities, some data provides interesting insights; in their study, Parritt and O'Callaghan [37] analyse the answers provided by a group of couple specialists and describe some aspects of their work with disabled patients: the first approach, feelings experienced during the therapy, the difference with working with patients who are not disabled, the possible use of supervision, etc. The authors report the difficulties that often therapists say they encounter in this type of work, bringing back feelings mirrored by those of their patients, such as: dips in mood, feelings of powerlessness, and feelings of anger and frustration. The data is also linked to two different types of reactions: on the one hand, a negative feeling that makes it difficult to approach these patients as less competent and less able to benefit from psychotherapy given their conditions of disability; on the other hand, it seems that the very disabling condition may elicit feelings of greater empathy and understanding that would facilitate the approach to the patient. The perception of the therapists seems dominated by the difficulty of integration between the "body" and the disabled "person". Moreover, among the categories of response, it reveals two of these particularly common areas: the sense of inadequacy of their professional skills in relation to disability and the perception that the peculiarities of life of the disabled patient get out of the frame of reference of the therapist; both require attention by the poor quality of the professionals and the need for more training on these topics [37].

Rarely is the couple perspective analysed. As claimed by Esmail, Esmail and Munro [34], the experience of the single partner is more likely to be analysed, whether it is disabled or healthy; in this way, however, an important point regarding the perception of the "We" of the couple is missed, something which is often different from that of the individual and certainly more complex to define but essential for more effective, systemic work. In the few studies available on the subject, it is claimed that the area of sexuality is what is most dramatically distorted by the 
impact of the disability of a partner, not just that people with disabilities are less likely to marry or to establish a relationship as a stable couple, but that they seem to have a greater chance of experiencing separation or divorce and that, where the couple can withstand the impact of the onset of a disability, sexual life is reduced or is a source of low satisfaction in both partners [38] [39]. Moreover, in relation to the perspective of the couple, the disability can also intervene on the levels of stress and bond quality of the couple subsystem; in their literature review, Esmail et al. [34] found mixed results with respect to the satisfaction of the couple: in some studies, it seems that when the couple is formed with the disability already presents, higher levels of satisfaction in the areas of sexuality, intimacy and affection are reported; further research, by contrast, shows no difference between the relationships formed before and after the disability [39]. Data variability is probably due to the presence of resilience, mutual commitment as well as loss and mourning, in couples who are living with the presence of disability.

In any case, the sexual functioning of the couple before the onset of the disease is an area that must necessarily be within the survey's counselor or therapist performing the treatment: Samelson and Hannon [35] consider it essential to support the couple in identifying different forms in which sexuality can be expressed beyond the mere physical act: helping patients in exploring new ways of expression of the erotic and passionate component of the relationship means to support them in giving continuity to an area of married life that threatens to come to an end abruptly, and sometimes irreparably, interrupted by disability [35].

Esmail et al. [34] describe also the five main components of sexuality: sensuality, intimacy, sexual identity, procreation and sexualisation, defining them as distinct parts of a whole, describing their mutual influence and highlighting the role exerted on all of them from the external environment in its family, socio-cultural, ethnic and religious dimensions. If the integration is high, then most functional and satisfactory will be the "sexual beingness" [34, p. 269]. Even Samelson and Hannon [35], when referring to a definition of Levine (1995 in ibidem) about sexuality as a system of emotional response that orients towards themselves and towards others, focus on this area in the broadest sense, disengaging from the idea that sexual satisfaction is necessarily linked to genital function and the presence of erotic fulfillment: the intervention on the couple with disabilities related to sexuality must be, therefore, intended to identify the worst affected dimensions (first of all, the desire dimension), and take on all of them through holistic and systemic intervention [35].

The importance of the work on the perception of sexuality, both individually and as a couple, is confirmed by the study of Taleporos and McCabe [40]. They point out that self-esteem on a sexual and bodily level and the level of satisfaction on the intimacy of the couple strongly influence the psychological well-being of the disabled person and the couple, more consistently than in people without disabilities. The authors also argue that, as in a virtuous cycle, increasing well-being and personal self-esteem results in "relapse", as the perception of sexual aspects of the individual and couple life is the most satisfying and rewarding [40]. Another interesting reflection of Esmail et al. [34] calls into question the multiple forms of disability that seem to have different effects on the sexual relationship: physical disability, in fact, seems to be better managed by the non-disabled partner, who is in great difficulty if a cognitive impairment is present, which often makes it difficult to experience intimacy and the meanings associated with it. It also seems that couples are able to reformulate their intimate relationship in terms of mutual caring, sharing interests and leisure and social activities rather than purely sexually adapting more easily to the loss of the erotic component of the relationship. Even Samuelson and Hannon [35] dwell on the type of disability in defining the consequences on the well-being of the couple; in particular, the authors show that the onset of diseases such as multiple sclerosis, lupus erythematosus or Parkinson's disease often occurs in a phase of the life cycle in which the couple can expect to live years of full health, years where the generative component involves many areas of sharing and in which sexual life is expected to be intense and satisfying. The acceptance and processing of the diagnosis thus appear rather hard and particularly difficult: after the first phase of disease onset, in which most of the physical and emotional energies of the two partners are involved in the assessment of diagnosis and in the beginning of treatment, the crisis seems to flare up with the knowledge of an uncertain future and a permanent impairment of "normality". The next step is the full manifestation of the disease and its chronic nature, in which the tasks of caregiving, adaptation to new physical conditions and the management of symptoms interfere 
heavily with the renovation of a previous sexual life. Foley et al. [41], focusing more on patients with multiple sclerosis, found that well-being, sexual satisfaction, effective communication and emotional closeness of the couple can be improved by couple therapy, particularly in the case in which the therapist is specially trained to treat couples with disabilities. In this case, the therapist needs to be aware of the importance of pre-existing couple dynamics, of the loan of the disease on individual and relational levels and he has to be prepared to work on the problems caused by any specific form of disability.

\section{CONCLUSION: A GLANCE AT ITALY}

The paper shows a different quality of services dedicated to disabled people. In Italy, compared to other European countries, there is a lack of opportunity for individuals with disabilities to benefit from professionals and in particular, from a sexual assistant. This professional figure in the Netherlands spread in the eighties, through the founding of the SAR by Vercoutre, and similarly in German-Switzerland, thanks to the association of Fachstelle Behinderung und für Sexualität, or in Switzerland, with the French Institute Sexualité et Handicaps Pluriel. Sexual assistance to a person with physical, intellectual or relational disabilities is aimed at the enrichment of psychophysical and emotional well-being.

A sexual service consists in a team of different professionals (such as: psychologists or sexologists and sexual assistants) who allows disabled people to get in touch with their intimacy and sexuality by exploring their bodies (for example, by stroking the body). Specifically, the sexual assistant and the psychologist can decide together how to proceed with the subject who needs assistance and then starting a sexual training [42].

The objective so has a therapeutic value: it is not to provide sexual pleasure and gratification, but rather to help the subject to face his/her social and physical relationships with more confidence, overcoming anxiety and fear that may prevent the achievement of emotional intimacy. In other words, it helps achieve sexual health and a good quality of sexual life as an objective set in 1975 by the World Health Organisation and considered the basis to achieving the well-being of a person. In fact, sexual pulsions (impulses), which are constantly repressed, hindered and not brought up in their date of occurrence, produce steady and progressive physical and psychological stress with healthy, and sometimes serious, consequences.

Sexual assistance to people with disabilities allows beneficiaries the opportunity to rediscover their own body as a source of pleasure, and not just suffering. In Italy, there is no legal recognition of this practice. In 2014 only, a Draft Law on "Dispositions on assisted sexuality for people with disabilities" was presented; it is aimed at the introduction of the sexual professional helper. A Professional (with psychological, medical or sexology training) who is "able to help people, with physical-motor, mental or cognitive disabilities, to feel erotic, sensual or sexual experiences and to better guide their internal energies, as well as often discharged dysfunctional feelings of anger and aggression". From the initiative of thirteen senators, the D.L. starts with a Constitutional Court ruling (No. 561/1987) which, among fundamental human rights, also recognises sexuality as a way of "expression of the human person", and is subject to protection (under Article 2 of the Italian Constitution). It is a right, which in some circumstances, is rather limited by the physical and psychological conditions of disabled people [43].

The sexual assistant in this way intervenes on both a physical and a psychological level, therefore, helping people with disabilities to feel sexual experiences. That is, performing a good quality of education in sexuality and affectivity; helping those who have lost motor skills (e.g. after an incident) to rediscover how to give and receive pleasure; allowing those born with a disability and who have never had any sexual experiences to experience these physically; teaching them to take care of the body even when the subject has physical or psychological limitations. These are just some of the situations for which the D.L. would provide sexual support. In many European countries, just a simple training course is required to become a sexual assistant. However, in Italy, institutional recognition is needed so that it can introduce such a profession from a formal point of view, in order to distinguish it from prostitution (after Merlino's Law 75/1958 and the regulation of prostitution in Italy). A lack of legislation that is opposed to greater awareness of the subject of disability in relation to sexuality and the growing acceptance of social consciousness; these are elements which also put into question the importance of educational training both for parents and professionals, with full respect for the dignity and rights of any beneficiary of sexual 
service. The discussion on possible forms of further discrimination remains open, as well as talk on the social conscience and if it suggests the need for a special service just as a way to resolve the problem of inaccessibility to the sexual life of disabled people. Moreover, which kind of stigma could characterise a sexual assistant in a country like Italy, strongly anchored to a "squared taboo" on sexuality and disability? How could sexual assistants stand by "sexual workers" in the Italian context? How can they protect themselves? These critical issues are also linked to the risk of transforming the disability into a business.

The aim of this paper was to reveal the "invisibility" of the sexuality and affectivity rights of people with disabilities. We think a long pathway should be undertaken, towards a dynamic process of change and greater flexibility aimed at improving the quality of life of disabled people, their family and community as well [44].

Human Rights and fundamental freedoms are universal and therefore apply unreservedly to disabled people and/or situations of disability (Conference of the United Nations on Human Rights- Vienna, 25th June 1993).

\section{COMPETING INTERESTS}

Authors have declared that no competing interests exist.

\section{REFERENCES}

1. Baratella $P$, Littamè $E$. I diritti delle persone con disabilità. Dalla Convenzione Internazionale ONU alle buone pratiche, Trento: Erickson; 2009. (Italian).

2. Anderson P, Kitchin R. Disability, space and sexuality: Access to family planning services. Social Science \& Medicine. 2000;51:1163-1173.

3. Baudrillard J. La società dei consumi. I suoi miti e le sue strutture,Bologna: II Mulino; 1976. (Italian).

4. Giordano W. Comunicazione, linguaggio e modelli culturali nell'era della globalizzazione. Napoli: Edizioni Scientifiche Italiane; 2004. (Italian).

5. Mannucci A. Comunicare con la mente e il corpo. Un messaggio educativo dai diversamente abili. Tirrenia (PI): Del Cerro; 2003. (Italian).

6. Facchinetti E, Bellotti A, Coppedè N. II fiore oscuro, Roma: Sensibili alle foglie; 2005. (Italian).
7. Bozuffi V. Psicologia dell'integrazione sociale: la vita delle persone con disabilità in una società plurale. Milano: Franco Angeli; 2006. (Italian).

8. Dallara G. Asessuati come gli angeli?: un primo piano sulla realtà dell'handicap. Cesena: il Ponte vecchio; 2006. (Italian).

9. Lamb B., Layzell, S. Disabled in Britain: A world apart. London: Scope; 1994.

10. Anderson P, Kitchin R. Disability, space and sexuality: access to family planning services. Social Science \& Medicine. 2000;51:1163-1173.

11. Cantelmi T, Russo P, Talli M. II sesso negato. Roma: Cisu; 2000. (Italian).

12. Garofalo Geymonat G. Sex work in Europe, Rivista II Mulino. 2011;2:91-299.

13. Garofalo Geymonat G. Vendere e comprare sesso. Bologna: II Mulino; 2014. (Italian).

14. Kijak R. The sexuality of adults with intellectual disability in Poland. Sex Disability. 2013;31(2):109-123. PubMed PMID: 23704799; PubMed Central PMCID: PMC3659277.

15. Uliveri $\mathrm{M},(\mathrm{Ed})$. Love Ability. L'assistenza sessuale per le persone con disabilità. Erickson: Torino; 2014. (Italian).

16. McRuer R, Mollow A. Sex and disability. Durham (NC): Duke University Press; 2012.

17. Alapack RJ. The splendor of seeing and the magic of touch. Bloomington: luniverse; 2012.

18. Salvarezza L. The pulsional defusion and destinations of sexuality beyond genitality. Kairòs. Revista da Faculdade. 2013;16:2331.

19. Casteel C, Martin SL, Smith JB, Gurka KK, Kupper LL. National study of physical and sexual assault among women with disabilities. Injury Prevention. 2008;14:8790.

20. Hughes $\mathrm{K}$, Bellis MA, Jones L, Wood S, Bates GP. Prevalence and risk of violence against adults with disabilities: A systematic review and meta-analysis of observational studies. The Lancet. 2012;379:1621-1629.

21. Plummer SB, Findley PA. Women with disabilities experience with physical and sexual abuse. Trauma, Violence and Abuse. 2012;15-29.

22. McCabe MP, Cummins RA, Deeks AA. Sexuality and quality of life among people 
with physical disability. Sexuality and Disability. 2000;18(2):115-123.

23. Werner S. Public stigma and the perception of rights: Differences between intellectual and physical disabilities. Research in Developmental Disabilities. 2015;38:262-271.

24. McConkey R, Ryan D. Experiences of staff in dealing with client sexuality in services for teenagers and adults with intellectual disability. Journal of Intellectual Disability Research. 2011;45(1):83-87.

25. Berman $H$, Harris D, Enright R, Gilpin M, Cathers T, Bukovy G. Sexuality and the adolescent with a physical disability: Understandings and misunderstandings. Issues in Comprehensive Pediatric Nursing. 1999;22(4):183-196.

26. Moin V, Duvdevany I, Mazor D. Sexual identity, body image and life satisfaction among women with and without physical disability. Sexuality and Disability. 2009;27:83-95.

27. Sorrentino AM. Figli disabili. Milano: Raffaello Cortina; 2009. (Italian).

28. Salonia G. La Psicoterapia della Gestalt e il lavoro sul corpo. Per una rilettura del fitness, In: S. Vero (ed), II corpo disabitato. Semiologia, fenomenologia e psicopatologia del fitness. Milano: Franco Angeli; 2008. (Italian).

29. Valtolina G. Famiglia e disabilità. Milano: Franco Angeli; 2000. (Italian).

30. Gay R.,Di Bona M. Eros e disabili. Milano: Ancora; 2007. (Italian).

31. Zanobini M, Usai MC. Psicologia della disabilità e della riabilitazione. Milano: Franco Angeli; 2007. (Italian).

32. Castelli G, Mariani V. L'educazione sessuale delle persone disabili. Milano: Ares; 2005. (Italian).

33. Lew-Starowicz M, Rola R. Prevalence of sexual dysfunctions among women with multiple sclerosis. Sex Disabil. 2013;31(2): 141-153. PubMed PMID: 23704801; PubMed Central PMCID: PMC3659270

34. Esmail S, Esmail Y, Munro B. Sexuality and disability: The role of health care professionals in providing options and alternatives for couples. Sexuality and Disability. 2002;19(4):267-282.

35. Samelson DA, Hannon R. Sexual desire in couples living with chronic medical conditions. The Family Journal. 1999;7(1): 29-38.

36. Jacobson DS. The sexuality and disability unit: Applications for group training. Sexuality and Disability. 2000;18(3):175177.

37. Parritt S, O'Callaghan J. Splitting the difference: An exploratory study of therapists' work with sexuality, relationships and disability. Sexual and Relationship Therapy. 2000;15(2):151-169.

38. DeVivo MJ, Richards JS. Marriage rates among persons with spinal cord injury. Rehabilitation Psychology. 1996;41(4): 321-329.

39. Kreuter M, Sullivan M, Dahllof AG, Siosteen A. Partner relationships, functioning, mood and global quality of life in persons with spinal cord injury and traumatic brain injury. Spinal Cord. 1998;36(4):252-261.

40. Taleporos G, McCabe M. The impact of sexual esteem, body esteem, and sexual satisfaction on psychological well-being in people with physical disability. Sexuality and Disability. 2002;20(3):177-183.

41. Foley WF, LaRocca NG, Sanders AS, Zemon V. Rehabilitation of intimacy and sexual dysfunction in couples with multiple sclerosis. Multiple Sclerosis Journal. 2001;7(6):417-421.

42. Casalini B. Disabilità, immaginazione e cittadinanza sessuale. Ethics \& Politics. 2013;15(2):301-320. (Italian).

43. Mc Grath M, Sakellariou D. Why has so little progress been made in the practice of occupational therapy in relation to sexuality? Am J Occup Ther. 2016;70(1): 7001360010:1-5.

DOI: 10.5014/ajot.2016.017707

PubMed PMID: 26709437

44. $\mathrm{Di}$ Nicola $\mathrm{V}$, Todarello $\mathrm{O}$. Alcune considerazioni in tema di affettività e sessualità nei disabili, Milano: Franco Angeli; 2002. (Italian).

(c) 2016 Garro et al.; This is an Open Access article distributed under the terms of the Creative Commons Attribution License (http://creativecommons.org/licenses/by/4.0), which permits unrestricted use, distribution, and reproduction in any medium, provided the original work is properly cited.

Peer-review history:

The peer review history for this paper can be accessed here: http://sciencedomain.org/review-history/13947 